\title{
Balance dysfunction and falls in people with lower limb arthritis: factors contributing to risk and effectiveness of exercise interventions
}

\author{
Pazit Levinger • Susannah Wallman • Keith Hill
}

Received: 22 August 2010 /Accepted: 18 August 2011 /Published online: 2 September 2011

(C) European Group for Research into Elderly and Physical Activity (EGREPA) 2011

\begin{abstract}
Chronic musculoskeletal conditions in the lower extremities, particularly arthritis, and the chronic pain associated with them, are independent risk factors for falls, with approximately $50 \%$ of people with arthritis reporting one or more falls. Despite this, few studies have specifically addressed balance dysfunction, falls risk and falls incidence in people with arthritis. This review aimed to identify potential factors contributing to the increased risk of falls in people with lower limb osteoarthritis or rheumatoid arthritis and to summarise the evidence base for effective exercise interventions targeted to reduce their risk of falls. A systematic search of the literature was conducted in February 2010 and included the following databases: MEDLINE (Ovid),
\end{abstract}

P. Levinger $(\bowtie) \cdot K$. Hill

Musculoskeletal Research Centre, Faculty of Health Sciences,

La Trobe University,

Bundoora,

Melbourne, VIC 3086, Australia

e-mail: p.levinger@latrobe.edu.au

e-mail: pazit_levinger@yahoo.com.au

S. Wallman

Arthritis Victoria,

263 Kooyong Rd, Elsternwick,

Melbourne, VIC 3185, Australia

e-mail: susannah.wallman@arthritisvic.org.au

K. Hill

Allied Health Division, Northern Health,

Melbourne, Australia

K. Hill

Preventive and Public Health Division,

National Ageing Research Institute,

Melbourne, Australia

e-mail: Keith.Hill@latrobe.edu.au
EMBASE, Cumulative Index to Nursing and Allied Health Literature, Allied and Complementary Medicine, Cochrane Library and PsycINFO. Only three studies that investigated exercise programmes for people with lower limb arthritis met all inclusion criteria, but none used falls as an outcome measure. To broaden the review, systematic reviews that assessed the effectiveness of exercise interventions for fall prevention in older people were also included. The presence of any form of lower limb arthritis and the associated consequences including pain, balance impairment, reduced muscle strength and reduced function are all associated with increased risk of falling. Due to the link between musculoskeletal pain and the increased risk of falls, further research needs to investigate which type of exercise programme will be effective in reducing the risk of falls in populations with arthritis in the lower limbs.

Keywords Falls · Elderly · Arthritis · Exercise

\section{Introduction}

Falls are among the most common cause of injury and hospital admissions in older people in Australia [1] and the leading cause of mortality and morbidity in people aged 65 years and over worldwide [2,3]. Falls among older people in the community have been identified as a major public health problem with an estimated $30 \%$ of community-dwelling adults over the age of 65 reporting one or more falls each year [4-7]. The cost to the health care system associated with falls-related hospitalisation constitutes a substantial proportion of the burden of disease and health expenditure [8,9]. Injuries sustained from falling not only have a negative impact upon function, 
independence and quality of life but are also one of the major predictors of need for residential care services. Recovery from falls is often difficult and can result in self-imposed functional limitations due to fear of future falls, which consequently may lead to post-fall anxiety syndrome, depression and social isolation $[10,11]$.

Studies have identified a large number of risk factors associated with the risk of falling. Risk factors are generally classified into extrinsic (environmental) and intrinsic (individual-related) factors [12, 13]. Falls usually result from an interaction of multiple factors, with the risk of falling increasing as the number of risk factors increases [3, 14]. Physiological factors such as lower extremity muscle weakness, gait and balance impairments and functional impairments have been strongly associated with the risk of falls and are often targeted in preventive programmes [3, 4, 15-20]. Although many factors contribute to the risk of falling, addressing preventable or reversible motor deficits through exercise programmes seems to be a key aspect for effective and successful intervention to reduce the risk of falls $[21,22]$.

Arthritis is one of the leading causes of disability among people aged 65 years and over in Australia and internationally [23, 24], with half of all people aged over 80 having some form of arthritis [25]. Arthritis and musculoskeletal conditions accounted for approximately \$23.9 billion of the health expenditure in Australia in 2007 and have been described as reaching epidemic levels [25]. Similar high costs and projections have been reported internationally [26]. Chronic musculoskeletal conditions in the lower extremities, particularly arthritis, and the chronic pain associated with them, have been shown to be independent risk factors for falls [4, 27-33]. Recent studies identified approximately $50 \%$ of samples of people with arthritis reported one or more falls in a 12-month period, which is higher than the $30-35 \%$ reported for older people living in the community [34-36]. Despite this, few studies have specifically addressed falls risk and falls incidence in people with arthritis and other musculoskeletal conditions. The purposes of this review were to identify potential factors contributing to the increased risk of falls for people with arthritis and related musculoskeletal conditions and to summarise the evidence base for effective exercise interventions targeted to reduce the risk of falls in this population.

\section{Method}

Inclusion and exclusion criteria

Randomised controlled trials, prospective studies and case-control studies published in English evaluating falls, falls risk and exercise interventions in older people living in the community with arthritis-related conditions were considered for inclusion. Studies assessing older people in residential care settings or hospital settings were excluded. The search was limited to arthritis-related conditions, primarily osteoarthritis and rheumatoid arthritis. However, findings from research involving these two common forms of arthritis are likely to be generalisable to people with other arthritic conditions affecting the lower limbs.

\section{Search strategy}

A systematic search of the literature was conducted in February 2010 and included the following databases: MEDLINE (Ovid), EMBASE, Cumulative Index to Nursing and Allied Health Literature, Allied and Complementary Medicine, Cochrane Library and PsycINFO. Reference lists of key studies and systematic reviews were also examined. The search was limited to the English language and included the following keywords: falls, arthritis, osteoarthritis, rheumatoid arthritis, exercise, exercise therapy and balance. An example of a search strategy utilised for this review is presented in the "Appendix".

\section{Review process}

All titles and abstracts identified in the database search were exported to EndNote version X3 (Thomson, Reuters, Carlsbad, CA, USA). Any duplicated references were deleted. Each title and abstract was initially reviewed by one reviewer, and papers not relevant to the review were excluded. Potentially relevant papers were retained and were reviewed by a second reviewer independently to determine suitability for inclusion.

\section{Results}

The literature search revealed over 3,000 potential studies. Only three studies (two randomised controlled trials and one pre-post design) of exercise interventions (home-based exercise programme, Tai $\mathrm{Chi}$ and aquatic exercise programme) aiming to reduce falls risk and improve balance in people with arthritis were identified that met all inclusion criteria $[35,37,38]$. To broaden the review, systematic reviews that assessed the effectiveness of exercise interventions for fall prevention in older people were also included [21, 22]. Further to this, relevant papers that investigated physical factors such as balance, strength and proprioception associated with arthritis and increased risk of falling were also included. 


\section{Discussion}

Physical factors associated with arthritis and increased risk of falls

\section{Balance and proprioception}

Balance is an integral part of daily activities and important for independent function in older people. The ability to perform functional activities is multifaceted and involves other important components such as muscle strength, proprioception and neuromuscular control. As part of the ageing process, physiological changes in the neuromuscular system such as reduction in muscle strength, proprioception, reaction time and other components of the sensory system affect balance control and consequently have an adverse effect on the functional ability of older people [39-42]. Balance impairment has been shown to be a risk factor for falls in older people [3, 19, 43-45], including a recent systematic review in community-dwelling older adults [43]. People with lower limb arthritis have been reported to have proprioceptive deficits and poor balance control compared with asymptomatic controls [46-49]. People with knee osteoarthritis showed increased postural sway as measured by the movement of the centre of pressure [47, 48] or by the use of clinical tests [50], poorer proprioceptive acuity of affected joints [51] and impaired sensorimotor function [52].

\section{Lower limb muscle weakness}

Loss of muscle mass and reduction of strength that occur with increasing age are important contributing factors to reduced function and increased falls risk. Epidemiological studies have reported that approximately $1 \%$ of muscle mass is lost per year after the fourth decade of life $[53,54]$. Muscle strength has been shown to be an important factor in balance and gait, and muscle weakness has been shown to be a risk factor for the occurrence of falls $[15,20,55,56]$. People with lower limb arthritis are commonly reported to have reduced muscle strength and poor muscle control compared with asymptomatic individuals [47, 51, 57-59]. Muscle weakness around the knee and hip for people with knee and hip arthritis has been reported to be present in between $20 \%$ and $70 \%$ of people for the knee $[47,51,59,60]$ and $20 \%$ to $31 \%$ for the hip $[57,58,61]$. The presence of arthritis negatively affects the structure and function of muscle integrity and sensory functions, which in turn are likely to influence balance and compromise the safe performance of daily activities.

\section{Pain and functional limitation}

Disease symptoms associated with arthritis, such as pain in the lower limb, are related to deficits in neuromuscular functioning and may be an important underlying mechanism contributing to increased risk of falls and disability. Musculoskeletal pain may predispose to falls as it contributes to muscle weakness and mobility limitation [62]. One study reported that musculoskeletal pain, particularly widespread pain, was shown to be substantial risk factors for falls with $60 \%$ increased risk of falls for women who had a significant symptom of arthritis and other musculoskeletal disorders [28]. Similarly, patients with hip pain had increased risk of falling (41\% reported retrospectively having fallen compared with $16 \%$ of controls) regardless of the presence or absence of radiographic signs of hip osteoarthritis [63]. An association between pain and dysfunction, but not radiographic osteoarthritis and physiological predictors of falls risk, was also reported in the Tasmanian Older Adult Cohort study [64]. Leveille and colleagues [27] examined the association between chronic musculoskeletal pain and the occurrence of falls and found that chronic pain in more than one location and increased pain severity were associated with greater risk of falls. In summary, the presence of any form of lower limb arthritis and the associated consequences including pain, balance impairment, reduced muscle strength and reduced function are all associated with increased risk of falling.

\section{Other falls risk factors}

People with lower limb arthritis may have a range of other health problems that also increase their risk of falling. For example, poor eyesight, polypharmacy and the use of psychotropic medications, vestibular (inner ear) problems and peripheral neuropathy can all increase the risk of falling, independent of whether a person has arthritis or not $[12,13,16,65]$. All falls risk factors should be identified, and where possible, interventions should be implemented to address these. This may involve assessment with a falls risk assessment tool such as the FROP-Com [66] or the Falls Quickscreen [67].

\section{Non-exercise interventions to reduce the risk of falls}

A number of single interventions have been shown to be effective in reducing falls in older people living in the community, using randomised trial methodology [22] (with some samples including a proportion of participants with 
arthritis). Examples of successful single interventions (other than exercise, which is discussed below) include:

- Improving vision through cataract surgery

- Psychotropic medication withdrawal

- Medication review and recommendations to reduce or change medications

- Enhanced care after discharge home from hospital

- Home safety modifications by a trained health professional for people with increased falls risk

In addition, multifactorial interventions, where two or more types of interventions are combined, often based on a detailed falls risk assessment have also been shown to be effective in a number of randomised trials, even in people with high falls risk [22].

\section{Exercise interventions to reduce the risk of falls in arthritis population}

Systematic reviews have highlighted the effectiveness of exercise interventions in the reduction of falls among older people living in the community [21,22]. Gillespie et al. reported that exercise programmes that contain two or more components (strength, balance, flexibility or endurance) are more effective in reducing the rate of falls and the number of people falling compared to a single exercise component interventions programmes [22]. Within the exercise interventions, multiple component group exercise, Tai Chi (as a group exercise) and individually prescribed multiple component exercise carried out at home were all effective in reducing both the rate of falls and risk of falling. Sherrington et al. reported that exercise interventions that include a balance component are more effective for falls prevention than other forms of exercises [21]. This review also identified that exercise dose $(>50 \mathrm{~h}$ cumulative exercise amount, irrespective of exercise frequency) is associated with the efficacy of exercise programmes. Although both systematic reviews provide evidence for the effectiveness of exercise in reducing falls in older people in the community [21, 22], none of the included randomised controlled trials in these reviews primarily target an arthritis population, and therefore, the effect of exercise interventions on the reduction of falls in people with lower limb arthritis remains unknown. Several studies have reported the presence of musculoskeletal conditions in their population demographic; however, they have not indicated the effectiveness of the intervention to these people as a separate sub-group [68-70].

Only three studies were identified which investigated the effect of exercise programmes (home-based exercise programme, Tai Chi and aquatic exercise programme) to improve balance and the risk of falls in people with lower limb osteoarthritis and rheumatoid arthritis [35, 37, 38]. Williams et al. used an individualised balance and strength exercise programme, together with a graduated walking programme, over a 4-month intervention for people with rheumatoid arthritis and osteoarthritis and reported a significant improvement in balance, mobility, activity level, fear of falling and reduction in falls risk. While this study provides promising results, it was not powered to evaluate whether the exercise intervention reduced falls and was not a randomised trial design [35]. Song et al., using a randomised control trial, investigated the effectiveness of a 6-month Tai Chi programme on knee extensor muscle strength and fear of falling in women with knee osteoarthritis [37]. A significant improvement in knee strength and reduced fear of falling were reported; however, the effectiveness of the programme in reducing the number of falls remains unknown. Similarly, 11 weeks of combined educational programme (focused on increase knowledge on fall risk factors and falls prevention strategies) and aquatic exercise (focused on mobility, strength and balance) resulted in improvement in falls efficacy [38]. A longer follow-up however is needed to investigate the effect of the combined intervention programme on falls prevention. Consequently, none of the above studies have evaluated the effectiveness of exercise or other falls prevention approaches in reducing falls in people with lower limb arthritis.

Despite the evidence that muscle weakness is a risk factor for falls [71], strength training with moderate or high intensity in isolation has not been shown to reduce risk of falls [21]. Since balance impairment is associated with increased fall risk [43] and resistance (strengthening), exercise alone has not been consistently shown to improve balance in older adults (based on limited evidence) [72], balance impairment may be a stronger risk factor and therefore important to include in intervention programmes for falls prevention. Nevertheless, strength exercises may be important for people with musculoskeletal conditions as they have been shown to improve pain and disability for people with osteoarthritis [73]. Non-surgical treatment for arthritis commonly includes exercises aiming to reduce symptoms, increase function and muscle strength and improve joint integrity, but usually do not incorporate balance assessment or balance training. Due to the association between pain and the occurrence of falls in people with arthritis, it is likely that a combined balance, strengthening, flexibility and functional retraining exercise programme may provide a holistic approach to optimising a range of health outcomes, including improved balance and reduced falls risk.

Exercise in warm water has a range of benefits for people with some forms of arthritis, although there have been no randomised trials evaluating the effectiveness of this exercise approach in reducing falls. However, water 
exercise programmes can include exercises that involve strengthening of lower limb muscles and balance-related activities, which have been shown to achieve significant improvements in balance performance and function in people with arthritis in a pre-post design study [74]. Randomised controlled trials are required to investigate whether water exercise programmes with a balance component can reduce falls in people with arthritis.

In summary, exercise is one of the most researched types of interventions that have been shown to be effective in reducing falls in older people. However, it is important to note that there are different types of exercise that have differing effects on reducing falls and other health outcomes and that rarely has the focus of exercise in falls prevention targeted people with arthritis. Balance exercises should form part of an exercise programme aiming to reduce falls.

\section{Barriers for exercise in people with arthritis}

The health benefits of physical activity on life expectancy and quality of life have been well established [75-77]. Despite the clear health benefits of physical activity, many people in the community are still living a sedentary lifestyle. The national physical activity recommendations for older Australians recommend that older people should do some form of physical activity irrespective of their age, weight, health problems or abilities [78]. Pain has been recognised as a major barrier for participation in physical activity and social interaction in people with arthritis [7982], with studies suggesting a strong association between pain, depression and anxiety [83, 84]. Pain affects people's mood and ability to perform daily life activities; this in turn can be transmitted into other areas of life, leaving people with more difficulty engaging in social and leisure activities [85]. Physical activity has been shown to improve quality of life, function and disability and can alleviate pain in people with musculoskeletal conditions [73, 86-88]. The beneficial effects of exercise, however, seem to decline over time due to problems with adherence [89]. Active involvement, motivation strategies and long-term goals should be implemented in the intervention programme to support long-term behaviour change and adherence to physical activity [90]. Other factors influencing physical activity participation in older people generally, which are likely to also be relevant to people with arthritis, include ease of access, the choice in type of physical activity programme (e.g. home versus centre based), cost and opportunity for social networking [91-93].

For people with painful lower limb joints associated with musculoskeletal conditions, incorrect exercise selection or performing exercises at too high intensity or dosage (for example doing too many repetitions of a specific exercise) might increase pain [94, 95]. The pre-post design home exercise and aquatic exercise studies that achieved improved balance, mobility and falls risk outcomes for people with osteoarthritis and rheumatoid arthritis reported no significant change in joint pain with these exercise programmes [35, 38]. People with arthritis affecting the lower limb joints with concerns about the best form of exercise to undertake should consider having an assessment by a trained health professional such as a physiotherapist or exercise physiologist to determine the most appropriate type and amount of exercise to commence with and how this can be progressed.

The attitudes and beliefs towards exercise in people with arthritis play a significant role in the participation and adherence to physical activity [96, 97]. Some common reasons given by people with arthritis and other chronic health conditions about why they do not participate in physical activity or exercise programmes include that they consider exercise could aggravate their condition, that their health status means that they should not participate in physical activity or exercise programmes [81, 82] and that they are 'too old'. As the recently Commonwealth Government-endorsed Australian recommendations for physical activity for older people highlight, none of these should be a barrier to participating in physical activity [78, 98] but health professional advice may be needed for those with concerns. Given the substantial evidence of the benefits of various forms of exercise (such as land-based exercise, aquatic, muscle strengthening and aerobic exercise) for people with arthritis in reducing pain and disability [73, 86-88, 99-103], exercises are unlikely to be harmful if prescribed based on an assessment of individual need.

\section{Clinical implications and recommendations}

Despite, the high prevalence of falls in people with arthritis, there is a paucity of studies that investigate exercise interventions to reduce falls for people with lower limb arthritis. While some general indications can be derived from the extensive falls prevention literature for older people generally (including that to reduce falls, the exercise programme should incorporate exercises that challenge the balance system), there are some unique characteristics of impairments associated with the various forms of lower limb arthritis that highlight the need for research specifically targeting people with lower limb arthritis. For example, if incorrect exercises are undertaken, if there is excessive joint loading or any exercise is performed too vigorously, it may aggravate joint pain, inflammation and swelling. Greater levels of care may need to be used when commencing a new type of exercise programme, such as a balance training programme, for people with lower limb arthritis. 
General recommendations from the American College of Sport Medicine focus on joint protection exercises and include low-impact activity and functional exercise strengthening, and avoidance of contact sports and other activities requiring prolonged one-legged stance or rapid action movement in people with symptomatic joints [104]. Exercise for people with lower limb arthritis therefore may need to be individually tailored to fit the person's need and to minimise the risk of aggravating their joint pain. Seeking medical and other health professional advice should be considered before starting a new type of exercise programme.

\section{Research gaps}

There is a clear need for quality randomised controlled trials to evaluate the effectiveness, cost effectiveness and factors influencing successful outcomes in improving balance, reducing falls and improving long-term outcomes for people with lower limb arthritis.

\section{Summary and key points}

- Falls prevention programmes that target single and multiple falls risk factors in older people have been shown to be successful in reducing falls. Similar approaches should be utilised to address non-arthritisrelated falls risk factors (e.g. cataracts and psychotropic medication use) in people with arthritis who present with these comorbidities or falls risk factors.

- The presence of any form of lower limb arthritis and the associated consequences including pain, balance impairment, reduced muscle strength and reduced function are all associated with increased risk of falling.

- There are no randomised controlled trials investigating exercise interventions to reduce falls in people with arthritis. Since there is a link between musculoskeletal pain and increased risk of falls, further research is required to investigate which type of exercise programme will be effective in reducing the risk of falls specifically in populations with lower limb arthritis.

- Pain can be a perceived barrier for exercise in people with arthritis. Given the considerable evidence of the benefits of exercise in reducing pain, exercise aiming at reducing disease symptoms may be an important component to be included in any intervention in this population.

- Clinicians and other health care professionals should aim to identify concerns of people with arthritis with regard to exercise and pain and provide support and information to strongly encourage participation in appropriate exercise programmes.
- Due to the benefits of exercise for pain reduction and physical functioning, regular moderate intensity exercise is safe and should be encouraged in individuals with arthritis. People with moderate to severe arthritis, or painful lower limb joints, should consult a physiotherapist or other health professional regarding the most appropriate exercises to reduce falls that are suitable for their level of symptoms and disease severity.

- An effective intervention programme for falls prevention for people with arthritis may need to include both balance exercises and exercises to reduce disease symptoms.

Acknowledgments Funding was provided by Arthritis Victoria for undertaking the review.

\section{Appendix}

\section{Example of search strategy from MEDLINE via OVID}

1. Aged/or Accidental Falls/or fall\$.mp. or Frail Elderly/ 1003787

2. Arthritis, Rheumatoid/or Arthritis/or arthritis.mp.

3. osteoarthritis.mp. or Osteoarthritis, Hip/or Osteoarthritis/ or Osteoarthritis, Knee/22564

4. 2 or 373393

5. Postural Balance/or balance.mp. 66435

6. exercise.mp. or Exercise/or Exercise Therapy/96268

7. orthoses.mp. or Orthotic Devices/2489

8. orthosis.mp. or Orthotic Devices $/ 2656$

9. orthotic.mp. 2432

10. 7 or 8 or 93091

11. 4 and 5803

12. rehabilitation.mp. or Rehabilitation/42324

13. 6 or 10 or 12136035

14. 5 or 6 or 10 or 12198141

15. 11 and 4 and 141281

16. limit 15 to English language 1138

\section{References}

1. Cripps R, Carman J (2001) Falls by the elderly in Australia: trends and data for 1998. Australian Institute of Health and Welfare, Canberra, pp 1-31

2. Lord SR, Sherrington C, Menz HB (2001) Falls in older people. Cambridge University Press, London

3. Tinetti ME, Speechley M, Ginter SF (1988) Risk factors for falls among elderly persons living in the community. N Engl J Med 319(26):1701-1707

4. Campbell AJ, Borrie MJ, Spears GF (1989) Risk factors for falls in a community-based prospective study of people 70 years and older. J Gerontol 44(4):M112-M117 
5. Dolinis J, Harrison JE, Andrews GR (1997) Factors associated with falling in older Adelaide residents. Aust N Z J Public Health 21(5):462-468

6. Morris M, Osborne D, Hill K, Kendig H, Lundgren-Lindquist B, Browning C, Reid J (2004) Predisposing factors for occasional and multiple falls in older Australians who live at home. Aust J Physiother 50(3):153-159

7. O'Loughlin JL, Robitaille Y, Boivin JF, Suissa S (1993) Incidence of and risk factors for falls and injurious falls among the community-dwelling elderly. Am J Epidemiol 137(3):342-354

8. Bradley C, Pointer S (2008) Hospitalisations due to falls by older people, Australia 2005-2006. Injury research and statistics. AIHW, Adelaide

9. Stevens JA, Corso PS, Finkelstein EA, Miller TR (2006) The costs of fatal and non-fatal falls among older adults. Inj Prev 12(5):290-295

10. Howland J, Peterson EW, Levin WC, Fried L, Pordon D, Bak S (1993) Fear of falling among the community-dwelling elderly. J Aging Health 5(2):229-243

11. Fessel KD, Nevitt MC (1997) Correlates of fear of falling and activity limitation among persons with rheumatoid arthritis. Arthritis Care Res 10(4):222-228

12. Rubenstein LZ, Josephson KR (2002) The epidemiology of falls and syncope. Clin Geriatr Med 18(2):141-158

13. Leipzig RM, Cumming RG, Tinetti ME (1999) Drugs and falls in older people: a systematic review and meta-analysis: I. Psychotropic drugs. J Am Geriatr Soc 47(1):30-39

14. Robbins AS, Rubenstein LZ, Josephson KR, Schulman BL, Osterweil D, Fine G (1989) Predictors of falls among elderly people. Results of two population-based studies. Arch Intern Med 149(7):1628-1633

15. Lord SR, Ward JA, Williams P, Anstey KJ (1994) Physiological factors associated with falls in older community-dwelling women. J Am Geriatr Soc 42(10):1110-1117

16. Tinetti ME, Inouye SK, Gill TM, Doucette JT (1995) Shared risk factors for falls, incontinence, and functional dependence. Unifying the approach to geriatric syndromes. JAMA 273(17):1348-1353

17. Callisaya ML, Blizzard L, Schmidt MD, McGinley JL, Srikanth VK (2010) Ageing and gait variability - a population-based study of older people. Age Ageing 39(2):191-197

18. Hill K, Schwarz J, Flicker L, Carroll S (1999) Falls among healthy, community-dwelling, older women: a prospective study of frequency, circumstances, consequences and prediction accuracy. Aust N Z J Public Health 23(1):41-48

19. Delbaere K, Van den Noortgate N, Bourgois J, Vanderstraeten G, Tine W, Cambier D (2006) The physical performance test as a predictor of frequent fallers: a prospective community-based cohort study. Clin Rehabil 20(1):83-90

20. Lord SR, McLean D, Stathers G (1992) Physiological factors associated with injurious falls in older people living in the community. Gerontology 38(6):338-346

21. Sherrington C, Whitney JC, Lord SR, Herbert RD, Cumming RG, Close JC (2008) Effective exercise for the prevention of falls: a systematic review and meta-analysis. J Am Geriatr Soc 56(12):2234-2243

22. Gillespie LD, Robertson MC, Gillespie WJ, Lamb SE, Gates S, Cumming RG, Rowe BH (2009) Interventions for preventing falls in older people living in the community. Cochrane Database Syst Rev (2):CD007146.

23. March LM, Bagga H (2004) Epidemiology of osteoarthritis in Australia. Med J Aust 180(5 Suppl):S6-S10

24. Verbrugge LM, Juarez L (2008) Arthritis disability and heart disease disability. Arthritis Rheum 59(10):1445-1457

25. Access Economics (2007) Painful realities: the economic impact of arthritis in Australia in 2007. Arthritis Australia, Sydney

26. Bitton R (2009) The economic burden of osteoarthritis. Am J Manag Care 15(8 Suppl):S230-S235
27. Leveille SG, Jones RN, Kiely DK, Hausdorff JM, Shmerling RH, Guralnik JM, Kiel DP, Lipsitz LA, Bean JF (2009) Chronic musculoskeletal pain and the occurrence of falls in an older population. JAMA 302(20):2214-2221

28. Leveille SG, Bean J, Bandeen-Roche K, Jones R, Hochberg M, Guralnik JM (2002) Musculoskeletal pain and risk for falls in older disabled women living in the community. J Am Geriatr Soc 50(4):671-678

29. Blake AJ, Morgan K, Bendall MJ, Dallosso H, Ebrahim SB, Arie TH, Fentem PH, Bassey EJ (1988) Falls by elderly people at home: prevalence and associated factors. Age Ageing 17(6):365-372

30. Lawlor DA, Patel R, Ebrahim S (2003) Association between falls in elderly women and chronic diseases and drug use: cross sectional study. BMJ 327(7417):712-717

31. Sturnieks DL, Tiedemann A, Chapman K, Munro B, Murray SM, Lord SR (2004) Physiological risk factors for falls in older people with lower limb arthritis. J Rheumatol 31(11):2272-2279

32. Schwartz AV, Villa ML, Prill M, Kelsey JA, Galinus JA, Delay RR, Nevitt MC, Bloch DA, Marcus R, Kelsey JL (1999) Falls in older Mexican-American women. J Am Geriatr Soc 47(11):1371-1378

33. Stalenhoef PA, Crebolder HF, Knottnerus JA, Van der Horst F (1997) Incidence, risk factors and consequences of falls among elderly subjects living in the community: a criteria-based analysis. Eur J Publ Health 7(3):328-334

34. Brand C, Juan AW, Lowe A, Morton C (2005) Prevalence, outcome and risk for falling in 155 ambulatory patients with rheumatic disease. J Rheumatol 8:99-105

35. Williams SB, Brand CA, Hill KD, Hunt SB, Moran H (2010) Feasibility and outcomes of a home-based exercise program on improving balance and gait stability in women with lower-limb osteoarthritis or rheumatoid arthritis: a pilot study. Arch Phys Med Rehabil 91(1):106-114

36. Levinger P, Menz HB, Wee E, Feller JA, Bartlett JR, Bergman NR (2011) Physiological risk factors for falls in people with knee osteoarthritis before and early after knee replacement surgery. Knee Surg Sports Traumatol Arthrosc 19(7):1082-1099. doi:10.1007/s00167-010-1325-8

37. Song R, Roberts BL, Lee EO, Lam P, Bae SC (2010) A randomized study of the effects of t'ai chi on muscle strength, bone mineral density, and fear of falling in women with osteoarthritis. J Altern Complement Med 16(3):227-233

38. Arnold CM, Faulkner RA (2010) The effect of aquatic exercise and education on lowering fall risk in older adults with hip osteoarthritis. J Aging Phys Act 18(3):245-260

39. Daubney ME, Culham EG (1999) Lower-extremity muscle force and balance performance in adults aged 65 years and older. Phys Ther 79(12):1177-1185

40. Doherty TJ, Vandervoort AA, Brown WF (1993) Effects of ageing on the motor unit: a brief review. Can J Appl Physiol 18 (4):331-358

41. Skinner HB, Barrack RL, Cook SD (1984) Age-related decline in proprioception. Clin Orthop Relat Res 184:208-211

42. Stevens KN, Lang IA, Guralnik JM, Melzer D (2008) Epidemiology of balance and dizziness in a national population: findings from the English Longitudinal Study of Ageing. Age Ageing 37(3):300-305

43. Muir SW, Berg K, Chesworth B, Klar N, Speechley M (2010) Quantifying the magnitude of risk for balance impairment on falls in community-dwelling older adults: a systematic review and meta-analysis. J Clin Epidemiol 63(4):389-406

44. Stalenhoef PA, Diederiks JP, Knottnerus JA, Kester AD, Crebolder HF (2002) A risk model for the prediction of recurrent falls in community-dwelling elderly: a prospective cohort study. J Clin Epidemiol 55(11):1088-1094

45. Maki BE, Holliday PJ, Topper AK (1991) Fear of falling and postural performance in the elderly. J Gerontol 46(4):M123M131 
46. Hassan BS, Doherty SA, Mockett S, Doherty M (2002) Effect of pain reduction on postural sway, proprioception, and quadriceps strength in subjects with knee osteoarthritis. Ann Rheum Dis 61 (5): $422-428$

47. Hassan BS, Mockett S, Doherty M (2001) Static postural sway, proprioception, and maximal voluntary quadriceps contraction in patients with knee osteoarthritis and normal control subjects. Ann Rheum Dis 60(6):612-618

48. Masui T, Hasegawa Y, Yamaguchi J, Kanoh T, Ishiguro N, Suzuki S (2006) Increasing postural sway in rural-community-dwelling elderly persons with knee osteoarthritis. J Orthop Sci 11(4):353-358

49. Ekdahl C, Andersson SI (1989) Standing balance in rheumatoid arthritis. A comparative study with healthy subjects. Scand J Rheumatol 18(1):33-42

50. Hinman RS, Bennell KL, Metcalf BR, Crossley KM (2002) Balance impairments in individuals with symptomatic knee osteoarthritis: a comparison with matched controls using clinical tests. Rheumatology (Oxford) 41(12):1388-1394

51. Hurley MV, Scott DL, Rees J, Newham DJ (1997) Sensorimotor changes and functional performance in patients with knee osteoarthritis. Ann Rheum Dis 56(11):641-648

52. Bennell KL, Hinman RS, Metcalf BR (2004) Association of sensorimotor function with knee joint kinematics during locomotion in knee osteoarthritis. Am J Phys Med Rehabil 83 (6):455-463, quiz 464-456, 491

53. Baumgartner RN, Koehler KM, Gallagher D, Romero L, Heymsfield SB, Ross RR, Garry PJ, Lindeman RD (1998) Epidemiology of sarcopenia among the elderly in New Mexico. Am J Epidemiol 147(8):755-763

54. Janssen I, Heymsfield SB, Wang ZM, Ross R (2000) Skeletal muscle mass and distribution in 468 men and women aged 1888 yr. J Appl Physiol 89(1):81-88

55. Wolfson L, Judge J, Whipple R, King M (1995) Strength is a major factor in balance, gait, and the occurrence of falls. $J$ Gerontol A Biol Sci Med Sci 50 Spec no: 64-67.

56. Lord SR, Clark RD, Webster IW (1991) Physiological factors associated with falls in an elderly population. J Am Geriatr Soc 39(12):1194-1200

57. Arokoski MH, Arokoski JP, Haara M, Kankaanpaa M, Vesterinen M, Niemitukia LH, Helminen HJ (2002) Hip muscle strength and muscle cross sectional area in men with and without hip osteoarthritis. J Rheumatol 29(10):2185-2195

58. Ekdahl C, Broman G (1992) Muscle strength, endurance, and aerobic capacity in rheumatoid arthritis: a comparative study with healthy subjects. Ann Rheum Dis 51(1):35-40

59. Fisher NM, Pendergast DR (1997) Reduced muscle function in patients with osteoarthritis. Scand J Rehabil Med 29(4):213-221

60. Slemenda C, Brandt KD, Heilman DK, Mazzuca S, Braunstein EM, Katz BP, Wolinsky FD (1997) Quadriceps weakness and osteoarthritis of the knee. Ann Intern Med 127(2):97-104

61. Madsen OR, Brot C, Petersen MM, Sorensen OH (1997) Body composition and muscle strength in women scheduled for a knee or hip replacement. A comparative study of two groups of osteoarthritic women. Clin Rheumatol 16(1):39-44

62. Lamb SE, Guralnik JM, Buchner DM, Ferrucci LM, Hochberg MC, Simonsick EM, Fried LP (2000) Factors that modify the association between knee pain and mobility limitation in older women: the Women's Health and Aging Study. Ann Rheum Dis 59(5):331-337

63. Nahit ES, Silman AJ, Macfarlane GJ (1998) The occurrence of falls among patients with a new episode of hip pain. Ann Rheum Dis 57(3):166-168

64. Foley SJ, Lord SR, Srikanth V, Cooley H, Jones G (2006) Falls risk is associated with pain and dysfunction but not radiographic osteoarthritis in older adults: Tasmanian Older Adult Cohort study. Osteoarthr Cartil 14(6):533-539
65. Lord SR, Dayhew J (2001) Visual risk factors for falls in older people. J Am Geriatr Soc 49(5):508-515

66. Russell MA, Hill KD, Blackberry I, Day LM, Dharmage SC (2008) The reliability and predictive accuracy of the falls risk for older people in the community assessment (FROP-Com) tool. Age Ageing 37(6):634-639

67. Bell E, Stirling C (2006) What tools help make "whole-ofpatient" practices happen?: a Tasmanian Falls Prevention Project. Holist Nurs Pract 20(3):130-136

68. Province MA, Hadley EC, Hornbrook MC, Lipsitz LA, Miller JP, Mulrow CD, Ory MG, Sattin RW, Tinetti ME, Wolf SL (1995) The effects of exercise on falls in elderly patients. A preplanned meta-analysis of the FICSIT Trials. Frailty and Injuries: Cooperative Studies of Intervention Techniques. JAMA 273 (17):1341-1347

69. Freiberger E, Menz HB, Abu-Omar K, Rutten A (2007) Preventing falls in physically active community-dwelling older people: a comparison of two intervention techniques. Gerontology 53(5):298-305

70. Lord SR, Ward JA, Williams P, Strudwick M (1995) The effect of a 12-month exercise trial on balance, strength, and falls in older women: a randomized controlled trial. J Am Geriatr Soc 43 (11):1198-1206

71. Moreland JD, Richardson JA, Goldsmith CH, Clase CM (2004) Muscle weakness and falls in older adults: a systematic review and meta-analysis. J Am Geriatr Soc 52(7):1121-1129

72. Orr R, Raymond J, Fiatarone Singh M (2008) Efficacy of progressive resistance training on balance performance in older adults: a systematic review of randomized controlled trials. Sports Med 38(4):317-343

73. Fransen M, McConnell S (2008) Exercise for osteoarthritis of the knee. Cochrane Database Syst Rev (4):CD004376.

74. Suomi R, Koceja DM (2000) Postural sway characteristics in women with lower extremity arthritis before and after an aquatic exercise intervention. Arch Phys Med Rehabil 81(6):780-785

75. Penedo FJ, Dahn JR (2005) Exercise and well-being: a review of mental and physical health benefits associated with physical activity. Curr Opin Psychiatr 18(2):189-193

76. Leitzmann MF, Park Y, Blair A, Ballard-Barbash R, Mouw T, Hollenbeck AR, Schatzkin A (2007) Physical activity recommendations and decreased risk of mortality. Arch Intern Med 167 (22):2453-2460

77. Franco $\mathrm{OH}$, de Laet C, Peeters A, Jonker J, Mackenbach J, Nusselder W (2005) Effects of physical activity on life expectancy with cardiovascular disease. Arch Intern Med 165 (20):2355-2360

78. Sims J, Hill K, Hunt S, Haralambous B (2010) Physical activity recommendations for older Australians. Australas J Ageing 29 (2):81-87

79. Rosemann T, Kuehlein T, Laux G, Szecsenyi J (2008) Factors associated with physical activity of patients with osteoarthritis of the lower limb. J Eval Clin Pract 14(2):288-293

80. Strahl C, Kleinknecht RA, Dinnel DL (2000) The role of pain anxiety, coping, and pain self-efficacy in rheumatoid arthritis patient functioning. Behav Res Ther 38(9):863-873

81. Shin YH, Hur HK, Pender NJ, Jang HJ, Kim MS (2006) Exercise self-efficacy, exercise benefits and barriers, and commitment to a plan for exercise among Korean women with osteoporosis and osteoarthritis. Int J Nurs Stud 43(1):3-10

82. Gyurcsik NC, Brawley LR, Spink KS, Brittain DR, Fuller DL, Chad K (2009) Physical activity in women with arthritis: examining perceived barriers and self-regulatory efficacy to cope. Arthritis Rheum 61(8):1087-1094

83. Katon W, Lin EH, Kroenke K (2007) The association of depression and anxiety with medical symptom burden in patients with chronic medical illness. Gen Hosp Psychiatry 29(2):147-155 
84. Patten SB, Williams JV, Lavorato DH, Modgill G, Jette N, Eliasziw M (2008) Major depression as a risk factor for chronic disease incidence: longitudinal analyses in a general population cohort. Gen Hosp Psychiatry 30(5):407-413

85. Machado GP, Gignac MA, Badley EM (2008) Participation restrictions among older adults with osteoarthritis: a mediated model of physical symptoms, activity limitations, and depression. Arthritis Rheum 59(1):129-135

86. Roddy E, Zhang W, Doherty M (2005) Aerobic walking or strengthening exercise for osteoarthritis of the knee? A systematic review. Ann Rheum Dis 64(4):544-548

87. Roddy E, Zhang W, Doherty M, Arden NK, Barlow J, Birrell F, Carr A, Chakravarty K, Dickson J, Hay E, Hosie G, Hurley M, Jordan KM, McCarthy C, McMurdo M, Mockett S, O'Reilly S, Peat G, Pendleton A, Richards S (2005) Evidence-based recommendations for the role of exercise in the management of osteoarthritis of the hip or knee - the move consensus. Rheumatology (Oxford) 44(1):67-73

88. Zhang W, Moskowitz RW, Nuki G, Abramson S, Altman RD, Arden N, Bierma-Zeinstra S, Brandt KD, Croft P, Doherty M, Dougados M, Hochberg M, Hunter DJ, Kwoh K, Lohmander LS, Tugwell P (2008) Oarsi recommendations for the management of hip and knee osteoarthritis, part II: Oarsi evidencebased, expert consensus guidelines. Osteoarthr Cartil 16(2): $137-162$

89. Fransen M, McConnell S, Bell M (2002) Therapeutic exercise for people with osteoarthritis of the hip or knee. A systematic review. J Rheumatol 29(8):1737-1745

90. Veenhof C, van Hasselt TJ, Koke AJ, Dekker J, Bijlsma JW, van den Ende CH (2006) Active involvement and long-term goals influence long-term adherence to behavioural graded activity in patients with osteoarthritis: a qualitative study. Aust J Physiother 52(4):273-278

91. Nies MA, Vollman M, Cook T (1998) Facilitators, barriers, and strategies for exercise in European American women in the community. Public Health Nurs 15(4):263-272

92. Schutzer KA, Graves BS (2004) Barriers and motivations to exercise in older adults. Prev Med 39(5):1056-1061
93. Cohen-Mansfield J, Marx MS, Guralink JM (2003) Motivators and barriers to exercise in an older community-dwelling population. JAPA 11:242-253

94. Resnick B (2001) Managing arthritis with exercise. Geriatr Nurs 22(3):143-150

95. Bennell KL, Hinman RS (2011) A review of the clinical evidence for exercise in osteoarthritis of the hip and knee. J Sci Med Sport 14(1):4-9

96. Gecht MR, Connell KJ, Sinacore JM, Prohaska TR (1996) A survey of exercise beliefs and exercise habits among people with arthritis. Arthritis Care Res 9(2):82-88

97. Hurley MV, Walsh N, Bhavnani V, Britten N, Stevenson F (2010) Health beliefs before and after participation on an exercisedbased rehabilitation programme for chronic knee pain: doing is believing. BMC Musculoskelet Disord 11:31

98. Australian Government of Health and Ageing Physical activity guidelines (2009) Available at http://www.health.gov.au/ internet/main/publishing.nsf/content/health-pubhlth-strategphys-act-guidelines\#rec_older. Accessed 15 Feb 2010

99. Callahan LF (2009) Physical activity programs for chronic arthritis. Curr Opin Rheumatol 21(2):177-182

100. Bartels EM, Lund H, Hagen KB, Dagfinrud H, Christensen R, Danneskiold-Samsoe B (2007) Aquatic exercise for the treatment of knee and hip osteoarthritis. Cochrane Database Syst Rev (4): CD005523.

101. Lange AK, Vanwanseele B, Fiatarone Singh MA (2008) Strength training for treatment of osteoarthritis of the knee: a systematic review. Arthritis Rheum 59(10):1488-1494

102. Fransen M, McConnell S, Hernandez-Molina G, Reichenbach S (2009) Exercise for osteoarthritis of the hip. Cochrane Database Syst Rev (3):CD007912.

103. Ottawa panel evidence-based clinical practice guidelines for therapeutic exercises and manual therapy in the management of osteoarthritis (2005) Phys Ther 85(9):907-971.

104. Minor MA, Kay DR (2009) Arthritis. In: Durstine JL, Moore GE, Painter PL, Roberts SO (eds) ACSM's exercise management for persons with chronic diseases and disabilities. Human Kinetics, Champaign 